\title{
Interactive comment on "Spatiotemporal
} variations in atmospheric aerosols in East Asia: Identifying local pollutants and transported Asian aerosols in Osaka, Japan using DRAGON" by Makiko Nakata et al.

\section{Makiko Nakata et al.}

nakata@socio.kindai.ac.jp

Received and published: 22 July 2016

Dear Reviewer,

Thank you very much for your great help of my manuscript "Spatiotemporal variations in atmospheric aerosols in East Asia: Identifying local pollutants and transported Asian aerosols in Osaka, Japan using DRAGON". The revision works are briefly summarized as follow;

1. The title was changed to "Identifying local pollutants and Asian aerosols transported to Osaka during DRAGON-Japan". 2. In order to investigate the origin of high PM 
concentration measured in Osaka in the evening of 11th March 2012, time variation maps of PM concentrations and back trajectory analysis are added to the manuscript. ACPD 3. Chapter titles are modified in chapter 2 and chapter 4. More detailed explanations of instruments are added in new section 2-2. 4. Ex-Figures 10,11, and 12 are replaced by new-Table 1 to clarify the results. 5. The manuscript is revised according to reviewer's comments.

Interactive

comment

Very sincerely yours, Makiko Nakata

Interactive comment on Atmos. Chem. Phys. Discuss., doi:10.5194/acp-2016-182, 2016. 